\title{
Estimation of Stem Carbon Stock of Selected Eucalyptus grandis Plantations in Up Country Sri Lanka
}

\author{
A.M.H.L. Aththanayake*, W.A.R.T.W. Bandara \\ Department of Zoology and Environmental Management, University of Kelaniya, Sri Lanka \\ *hlaththanayake@gmail.com
}

\begin{abstract}
Plantation forestry plays an important role in mitigating global warming and climate change by sequestering carbon dioxide in their biomass. Eucalyptus grandis is an important timber species in plantation forestry in Sri Lanka. The objectives of the present study were to estimate the stem carbon stock, the total amount of atmospheric carbon dioxide sequestered in stems and the monetary value of carbon sequestered in stems of selected E. grandis plantations in upcountry Sri Lanka. Four study sites were selected from Kandapola, Bogawanthalawa, Haputhale and Pinnawala to represent upcountry, intermediate zone and wet zone where E. grandis is confined to. Each plantation was divided into three strata and 0.05 ha circular sample plot was laid out in each stratum. Each individual in the plot was measured for total tree height and diameter at breast height (dbh). The carbon content of each $E$. grandis stem of individuals in the plantations was calculated using a constructed model to predict stem carbon of $E$. grandis, in which the explanatory variables are total tree height and dbh. Thereby total stem carbon stock of each plantation was estimated. Total amount of atmospheric carbon dioxide sequestered in all the E. grandis stems of each plantation and monetary value of carbon sequestered in each stem were thereby calculated for each plantation. The lowest value of estimated amount of carbon sequestered in E. grandis stems per hectare was observed in Kandapola plantation (28.176 t/ha) while the highest value was observed in Pinnawala plantation (504.095 t/ha). The highest value of estimated total stem carbon stock of a plantation was observed in Bogawanthalawa plantation (17,390.669 t). For estimated amount of atmospheric carbon dioxide sequestered in E. grandis stems, the lowest value was observed in Kandapola plantation (103.405 t/ha) while the highest value was observed in Pinnawala plantation $(1,850.027 \mathrm{t} / \mathrm{ha})$. The highest value of estimated total amount of atmospheric carbon dioxide sequestered in the stems of a plantation was observed in Bogawanthalawa plantation $(63,823.757 \mathrm{t})$. When considering the monetary value of carbon stock in $E$. grandis stems, the lowest estimated value was observed in Kandapola plantation $(3,803.72$ Rs./ha) while the highest value was observed in Pinnawala plantation (68,052.76 Rs./ha). When considering plantation wise carbon stock, the highest value of estimated monetary value was observed in Bogawanthalawa plantation (Rs. 2,347,740.37). These estimates shall be presented to assess the carbon dynamics in E. grandis plantations in upcountry Sri Lanka.
\end{abstract}

Keywords: Eucalyptus grandis, Carbon sequestration, Climate change, Carbon stock 